\title{
Ensuring center quality, proper patient selection and fair access to chimeric antigen receptor T-cell therapy: position statement of the Austrian CAR-T Cell Network
}

\author{
Hildegard T. Greinix · Andishe Attarbaschi · Michael Girschikofsky · Richard Greil • Wolfgang Holter · \\ Peter Neumeister - Christina Peters · Andreas Petzer · Jakob Rudzki · Peter Schlenke · Clemens A. Schmitt · \\ Wolfgang Schwinger · Dominik Wolf · Nina Worel · Ulrich Jaeger
}

Received: 27 January 2020 / Accepted: 28 January 2020 / Published online: 20 February 2020

(C) The Author(s) 2020

Summary Chimeric antigen receptor $\mathrm{T}$ cells (CAR-T cells) are a novel form of cellular immunotherapy for patients with hematologic and oncologic malignancies. Known side effects of these approved cellular immunotherapies are cytokine release syndrome, immune-cell associated neurotoxicity syndrome, cytopenias, infections and long-lasting B cell aplasia. Safe administration of CAR-T cell therapy requires thorough patient selection and patient care in qualified CAR-T cell centers.
Keywords CAR-T cells · Position statement Network · Patient selection criteria · Infrastructure requirements

Abbreviations

ASCTR Austrian Stem Cell Transplant Registry

B-ALL B-cell acute lymphoblastic leukemia

CAR-T Chimeric antigen receptor-T cell

CD19 Cluster of differentiation 19

CRS Cytokine release syndrome

DLBCL Diffuse large B cell lymphoma

EBMT European Society for Blood and Marrow Transplantation

Dr. J. Rudzki · Univ. Prof. Dr. D. Wolf

Division of Hematology, Medical University Innsbruck, Anichstraße 35, 6020 Innsbruck, Austria

Univ. Prof. Dr. P. Schlenke

Department of Blood Group Serology and

Transfusion Medicine, Medical University Graz, Auenbruggerplatz 36, $8036 \mathrm{Graz}$, Austria

Univ. Prof. Dr. C. A. Schmitt

Department of Internal Medicine 3-Hematology and Oncology, Kepler University Clinic, Linz, Austria

Univ. Prof. Dr. W. Schwinger

Division of Pediatric Hematology and Oncology, Medical University Graz, Auenbruggerplatz 36, 8036 Graz, Austria

Univ. Prof. Dr. N. Worel

Department of Blood Group Serology and Transfusion

Medicine, Medical University Vienna, Waehringer Guertel 18-20, 1090 Vienna, Austria

Univ. Prof. Dr. U. Jaeger

Division of Hematology, Medical University Vienna, Waehringer Guertel 18-20, 1090 Vienna, Austria 
EMA European Medicines Agency

HSCT Hematopoietic stem cell transplantation

ICANS Immune-cell associated neurotoxicity syndrome

ICU Intensive care unit

PMBCL Primary mediastinal B cell lymphoma

SOPs Standard operating procedures

\section{Introduction}

Chimeric antigen receptor $\mathrm{T}$ cells (CAR-T cells) are a novel form of cellular immunotherapy for patients with hematologic and oncologic malignancies. Thereby patients' immune cells are harvested by leukapheresis, genetically modified to selectively express a tumor-specific surface receptor using a retroviral or lentiviral vector, expanded ex vivo and then reinfused into the patients after proper quality control measures and administration of lymphodepleting therapy [1]. These genetically modified T lymphocytes selectively recognize antigens on the surface of tumor cells against which they are directed and eradicate malignant cells after $\mathrm{T}$ cell activation [1].

So far, two commercial CAR-T cell products have been approved by the European Medicines Agency (EMA) which contain a CAR against CD19, a surface antigen of B-lymphocytes. Tisagenlecleucel $\left(K_{y m r i a h}{ }^{\circledR}\right)$ has been approved for therapy of children and young adults up to the age of 25 years with B cell acute lymphoblastic leukemia (B-ALL) and for adult patients with diffuse large B cell lymphoma (DLBCL); axicabtagen ciloleucel (Yescarta ${ }^{\circledR}$ ) has been approved for patients with DLBCL and primary mediastinal large cell B cell lymphoma (PMBCL). Of note, all patients have to have relapsed or refractory disease $[2,3]$.

Known side effects of these approved cellular immunotherapies are cytokine release syndrome (CRS), immune-cell associated neurotoxicity syndrome (ICANS), cytopenias, infections and longlasting B cell aplasia [4]. Incidence and severity of these side effects differ individually and between cell products. Life-threatening disease with multiorgan failure and severe cerebral edema have been reported from clinical studies. Therefore, safe administration of CAR-T cell therapy requires thorough patient selection and patient care in a qualified CAR-T cell center $[5,6]$.

We reasoned that a network of all centers involved in administration of CAR-T cells would be most suited to achieve the following aims:

- Ensure fair access for all citizens to all products

- Selection of patients with a high likelihood of response

- To avoid unjustified hopes for individual patients who are likely NOT to respond

- Ensure wise use of resources

- Country-wide registration and outcome control
- Retrospective analysis of predictive factors, product differences (real world evidence)

- To create a network for clinical and basic studies

- To avoid hospital tourism

The following criteria for patient selection and infrastructure of CAR-T cell centers have been developed within the CAR-T cell platform of the Austrian Society of Hematology and Medical Oncology (OeGHO) including the prerequisites for quality-controlled administration of CAR-T cell therapy in Austria. At least yearly or in case of new scientific developments and approvals this position statement will be updated.

The institution responsible for CAR-T cell therapy has to have specialized knowledge on therapy of patients with the malignancies to be treated, competency in cellular therapy including use of gene-modified cells and competency in intensive care to allow treatment of severe complications.

To guarantee therapeutic access for all Austrian patients CAR-T cell centers should be established that have all these competencies and fulfill the necessary structural requirements to be described in more detail in the following.

The requirements of regulatory authorities for the currently available CAR-T cell products have to be established. Most importantly, quality measures necessary for qualification of centers and the qualification by itself have to be achieved prior to use of CAR-T cells.

All CAR-T cell centers have to fulfill the following criteria regarding infrastructure, personal, and procedures. The medical head is responsible for the coordination and administration of CAR-T cell therapies. Within a center a well-organized, controlled, interdisciplinary and multiprofessional cooperation has to be in place for administration of CAR-T cell products.

\section{Criteria for infrastructure of CAR-T cell centers}

\section{Medical expertise}

Personal has to have extensive experience in therapy of the malignant disease to be treated with CAR-T cells, experience with clinical study participation and administration of experimental therapies.

For documentation of extensive experience in cellular therapy at a given center, first allogeneic and/or autologous hematopoietic stem cell transplantations (HSCT) had to be reported to the Austrian Stem Cell Transplant Registry (ASCTR) and the European Society of Blood and Marrow Transplantation (EBMT) during the last 3 years.

Each CAR-T cell center needs to have extensive experience in intensive care of patients with hematologic and oncologic diseases including the availability of 24-hour endoscopy, bronchoscopy, invasive pulmonary support and renal replacement therapy. Furthermore, standard operating procedures (SOPs) for 
management of complications of CAR-T cell therapy have to be in place including the use and 24-hour availability of tocilizumab as requested by regulatory authorities. An immediate transfer to and admission at an intensive care unit (ICU) if necessary has to be established.

\section{Additional criteria for infrastructure}

\section{Hygiene}

Prior to the infusion of CAR-T cells a lymphodepleting chemotherapy is administered resulting in immunosuppression and side effects known from patients with lymphoma and acute leukemia given similar therapies. Following CAR-T cell therapies patients can experience neutropenia and need appropriate supportive care. If necessary, immediate contact isolation during hospital stay has to be available.

CAR-T cell therapies have to be administered in defined hospital rooms according to regulatory requirements and their approval concerning handling of genetically modified microorganisms at a safety level 1 according to Austrian gene technique legislation.

\section{Pharmacy/Tissue bank}

The responsible pharmacy/tissue bank has to be included into the CAR-T cell center to allow timely fulfillment of all regulatory requirements.

\section{Waste disposal}

All materials in contact with the CAR-T cell product or included in it have to be handled as potentially infectious according to local regulatory requirements on biologic safety and have to be disposed accordingly. Unused CAR-T cells have to be handled according to local requirements on biology safety in accordance with its product information.

\section{Outpatient care}

For outpatient care a physician of the CAR-T cell center has to be always available. It has to be guaranteed that the patients are seen in rooms equipped for the outpatient care of immunosuppressed individuals. The rooms have to allow separation of patients with transmissible infections for diagnostic procedures and therapy. An appropriate infrastructure for administering intravenous medication and transfusion of blood products has to be available. Furthermore, a physician of the CAR-T cell center who is able to care for patients according to the SOPs defined by the CAR-T cell platform should be always available for follow-up of treated patients. This includes also prophylaxis and therapy of long-term side effects such as hypogammaglobulinemia, opportunistic infections and neurologic toxicities.

\section{Criteria for personnel}

The involved medical personnel (physicians and nursing staff) has to be thoroughly trained and has to have documented experience in administration of cytotoxic and immunosuppressive agents as well as cryopreserved cells.

The medical head and his/her deputy responsible for CAR-T cell therapy of adult patients have to be certified specialists for internal medicine and hematology/medical oncology. They must have at least 2 years of professional experience in a unit treating patients with severe immunodeficiency and/or performing allogeneic HSCT.

The medical head and his/her deputy responsible for CAR-T cell therapy of children and adolescents until the age of 18 years have to be certified specialists for pediatric hematology and oncology.

Certified medical specialists (Internal Medicine, Hematology and Medical Oncology for adults; pediatrics, pediatric hematology and oncology) have to be constantly available for inpatient and outpatient care of patients given CAR-T cell therapy. On weekends a physician on call has to be immediately available.

In view of the reported neurotoxicity of the currently approved CAR-T cell products it is of utmost importance to have qualified specialists of neurology trained about the side effects of CAR-T cells as members of the CAR-T cell center available who can immediately participate in the interdisciplinary management of patients both during inpatient as well as outpatient stay.

\begin{tabular}{|c|c|c|}
\hline \multicolumn{3}{|c|}{ Major criteria } \\
\hline 1. & Cardiac function & $E F>50 \%$ \\
\hline 2. & Lung function & $\mathrm{SpO}_{2}>91-92 \%$ at room air \\
\hline 3. & ECOG PS & $0-1$ \\
\hline \multirow[t]{2}{*}{4.} & \multirow[t]{2}{*}{ CNS } & No active/symptomatic involvement \\
\hline & & $\begin{array}{l}\text { No major neurologic disease as contraindica- } \\
\text { tion }\end{array}$ \\
\hline 5. & Infection & No active or uncontrolled infection \\
\hline \multicolumn{3}{|c|}{ Minor criteria } \\
\hline 6. & ANC & $\mathrm{G} / \mathrm{L} \geq 1.0$ \\
\hline 7. & ALC & $\mathrm{G} / \mathrm{L}>0.1-0.3$ \\
\hline 8. & NFP & $\mathrm{eGFR} \geq 60 \mathrm{~mL} / \mathrm{min} / 1.73 \mathrm{~m}^{2}$ \\
\hline 9. & LFP & S-ALT/AST $<2.5 \times$ ULN \\
\hline 10. & LFP & Total bilirubin $<2.0 \mathrm{mg} / \mathrm{dL}$ \\
\hline 11. & PIt & $\mathrm{G} / \mathrm{L} \geq 50-75$ \\
\hline 12. & $\mathrm{Hb}$ & $\mathrm{g} / \mathrm{dL}>8.0$ \\
\hline
\end{tabular}

EF ejection fraction, $\mathrm{SpO}_{2}$ oxygen saturation, ECOG PS Eastern Cooperative Oncology Group Performance Score, CNS central nervous system, $A N C$ absolute neutrophil count, G/L giga/liter, eGFR glomerular filtration rate, $S$-ALT/AST serum alanin-aminotransferase/ serum aspartat-aminotransferase, ULN upper level normal, ALC absolute lymphocyte count, NFP renal function profile, LFP liver function profile, Plt platelets, $g / d L \mathrm{~g} / \mathrm{dl}$, $\mathrm{Hb}$ Hemoglobin 


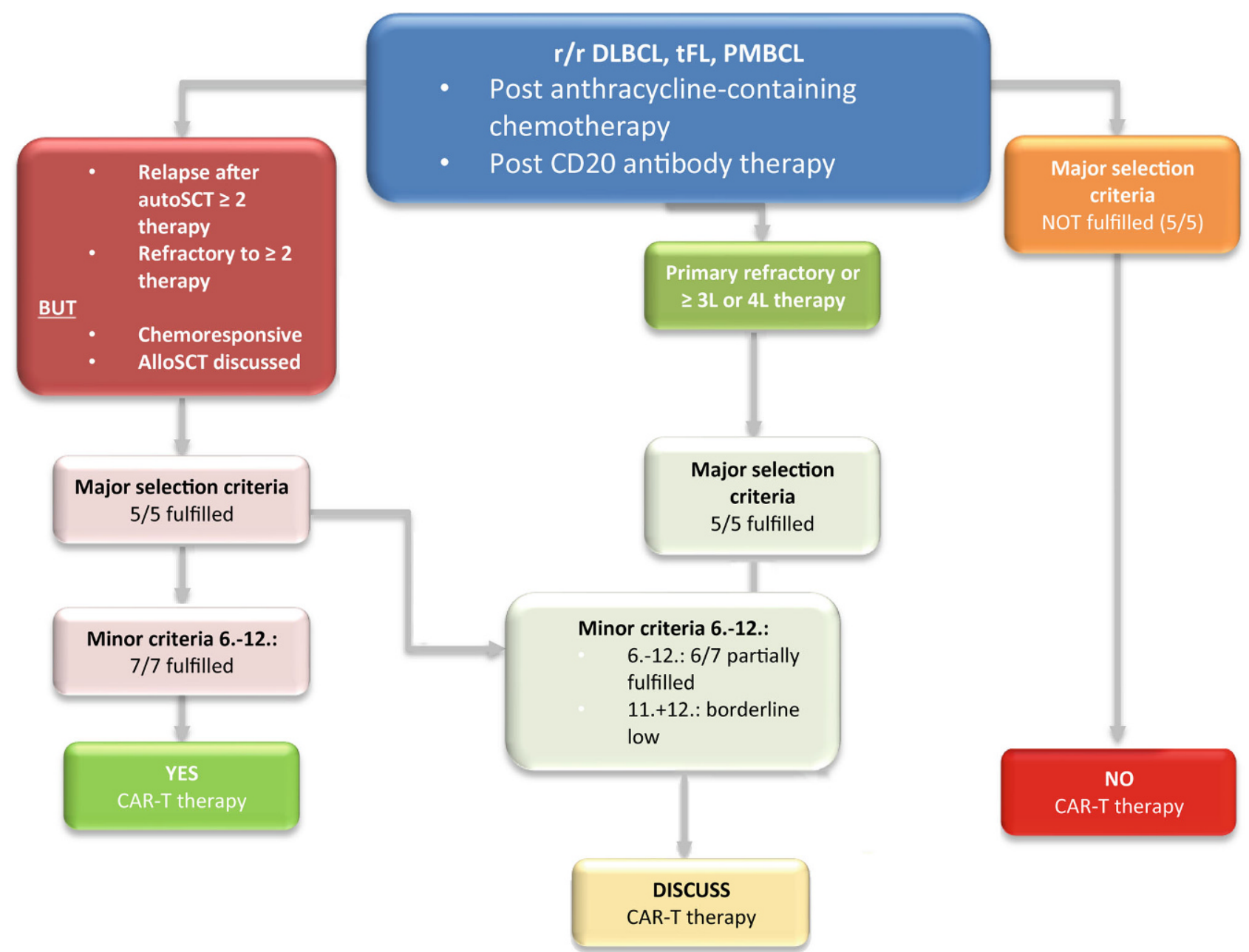

Fig. 1 Selection process for routine chimeric antigen receptor $\mathrm{T}(\mathrm{CAR}-\mathrm{T})$ cell patients. $r / r \mathrm{DLBCL}$ relapsed/refractory diffuse large B-cell lymphoma, $t F L$ transformed follicular

In case of transfer to an ICU it has to be guaranteed that the patient is seen on a daily basis during rounds by a specialist of hematology/medical oncology, in case of patients below the age of 18 years a specialist of pediatric hematology/oncology. This specialist has to discuss the treatment strategy during the ICU stay.

In addition, the following specialists have to be available:

Ophthalmology, head, neck and ear disease, cardiology, laboratory medicine, microbiology (availability within $24 \mathrm{~h}$ ), neurosurgery, psychiatry, radiology (CT scan and MRI) and urology.

For nursing staff the following qualifications are necessary:

The Head Nurse and her/his deputy on the patient ward responsible for CAR-T cell recipients have to have a diploma on nursing care with hematologic-oncologic qualifications or previous fulltime employment for at least 36 months on a hematologic-oncologic ward and have to participate in the center's internal training program on CAR-T cell therapy. lymphoma, $P M B C L$ primary mediastinal B-cell lymphoma, SCT stem cell transplantation, $L$ line

During each shift a qualified nurse who has at least 12 months of fulltime work experience on a hematologic-oncologic ward, with experience in administering chemotherapy to leukemia and lymphoma patients and who has participated in the center's internal training program on CAR-T cell therapy has to lead the nursing team.

Since patients will have to be transferred to ICUs the nursing staff of the ICU taking care of these patients has to be trained as well.

\section{Criteria for work processes}

\section{Technical equipment}

A specification and qualification of all processes, equipment and materials used for harvest, labeling and storage of blood cells and genetically modified cells has to be in place. For harvest and processing of leukocytes to be send to the CAR-T cell production facility an authorization of AGES has to be obtained. In case of use of nonapproved CAR-T cells an authorization for production has to be in place. 


\section{SOPS}

A CAR-T cell center has to have written descriptions, training on and documentation of clinical SOPs as well as documentation and reporting of side effects in place.

SOPs have to be available for clinical, radiologic and serologic surveillance for early detection of CRS and ICANS, transfer of patients to the ICU and management of CRS and neurotoxicity of all grades.

\section{Plan for qualification}

The existence and the continuous revision of a riskadapted qualification plan based on regulatory requirements and the current state of science and including all central aspects of administration of CAR-T cells has to be in place.

\section{Quality assurance}

Members of the CAR-T cell center should participate in quality assurance measures offered by national and international research institutions, pharmaceutical industry and regulatory authorities.

\section{Tumor board and patient selection}

Patients will be presented and discussed in tumor boards according to the Austrian recommendations (OeSG, Onkologiebeirat) and requirements of local hospitals.

A guidance document produced by the Austrian CAR-T Cell Network for patient selection is provided and will be updated regularly (Table 1 and Fig. 1).

\section{Registry}

Documentation is requested by EMA as part of the approval process for pharmaceutical companies. Centers must fulfill the requirements regarding personnel and infrastructure for participation in the registry module for CAR-T cells of the ASCTR and the registry of the EBMT. They have to insure timely documentation and reporting. Documentation of patient relevant data and side effects should be financed by the producers of CAR-T cells.

\section{Take Home Message}

Qualified CAR-T cell centers with defined infrastructure allow safe administration of CAR-T cell products.

Immediate and long-term care of CAR-T cell recipients by qualified medical staff has to be in place in every CAR-T cell center.

A network of CAR-T cell centers will ensure proper patient selection and fair access.

Funding Open access funding provided by Medical University of Graz.

Conflict of interest H.T. Greinix received honoraria for presentations at scientific meetings and consultancy from Celgene, Novartis and Janssen. U. Jaeger declares honoraria and research grants from Novartis, Gilead, Celgene, Miltenyi and Janssen. A. Attarbaschi is a consultant for Jazz Pharmaceuticals and Novartis; travel and accommodation expenses were covered by Jazz Pharmaceuticals, Amgen and Pfizer. M. Girschikofsky is a consultant for Celgene. C. Peters works at the speakers bureau and advisory board for Novartis and Amgen. A. Petzer received honoraria from Novartis, Gilead, Celgene and Janssen-Cilag; travel support from Gilead and Janssen-Cilag. J. Rudzki works at the speakers bureau for BMS/ Celgene, Roche, MSD, AstraZeneca, Amgen, Gilead and Novartis; is on the advisory board for Roche, MSD, AstraZeneca, Amgen, Gilead, Novartis and BMS/Celgene. N. Worel works at the speakers bureau for Novartis and Gilead; gets travel support from Novartis and Celgene; is on the advisory board for Novartis and Celgene. R. Greil, W. Holter, P. Neumeister, P. Schlenke, C.A. Schmitt, W. Schwinger and D. Wolf declare that they have no competing interests.

Open Access This article is licensed under a Creative Commons Attribution 4.0 International License, which permits use, sharing, adaptation, distribution and reproduction in any medium or format, as long as you give appropriate credit to the original author(s) and the source, provide a link to the Creative Commons licence, and indicate if changes were made. The images or other third party material in this article are included in the article's Creative Commons licence, unless indicated otherwise in a credit line to the material. If material is not included in the article's Creative Commons licence and your intended use is not permitted by statutory regulation or exceeds the permitted use, you will need to obtain permission directly from the copyright holder. To view a copy of this licence, visit http://creativecommons.org/licenses/by/4.0/.

\section{References}

1. JuneCH, etal. CART cellimmunotherapyforhuman cancer. Sciene. 2018;359:1361-5.

2. EMA/462626/2018 (2018). https://www.ema.europa.eu/ medicines/human/EPAR/kymriah. Accessed February 11, 2020

3. EMA/52410/2020 (2018). https://www.ema.europa.eu/ medicines/human/EPAR/yescarta. Accessed February 11, 2020.

4. Lee DW, Santomasso BD, Locke FL, et al. ASTCT consensus grading for cytokine release syndrome and neurologic toxicity associated with immune effector cells. Biol Blood MarrowTransplant. 2019;25(4):625-38.

5. Hopfinger G, Jäger U, Worel N. JCAR-T cell therapy in diffuse large B cell lymphoma: hype and hope. Hemasphere. 2019;3(2):e185. https://doi.org/10.1097/HS9. 0000000000000185 .

6. EHA Guidance document: The process of CAR-T cell therapy in Europe. Hemasphere. 2019 Aug 7;3(4):e280. https:// doi.org/10.1097/HS9.0000000000000280. eCollection2019 Aug. No abstract available.

Publisher's Note Springer Nature remains neutral with regard to jurisdictional claims in published maps and institutional affiliations.

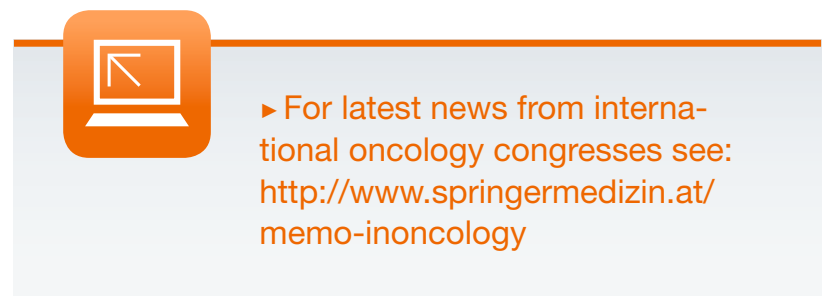

